\title{
Thermal Simulation for Geometric Optimization of Metallized Polypropylene Film Capacitors
}

\author{
M. H. El-Husseini, Pascal Venet, Gérard Rojat, and Charles Joubert
}

\begin{abstract}
In this paper, we use an analytic model to calculate the losses in the metallized polypropylene film capacitors. The model is validated experimentally for capacitors having the same capacitance but different geometry. For each group of capacitors a temperature distribution in the roll is assumed with the aim of optimizing its thermal performance. It appears that the heating of a long capacitor is higher than that of an equivalent flat capacitor subjected to the same electric stresses.
\end{abstract}

Index Terms-Equivalent series resistance, metallized film capacitors, optimization, polypropylene, thermal simulation.

\section{INTRODUCTION}

$\mathbf{T}$ HE polypropylene capacitors are used in industry due to their low production cost and high reliability [1], [4]. Metallized polypropylene (MPP) film capacitors are made of two polypropylene films coated with zinc or aluminum of a few nanometer's thickness rolled over an isolated support (mandrel). On each rolled face a zinc alloy is sprayed by a process called schooping, then connections are made (see Fig. 1) [4]-[6].

\section{LOSSES IN CAPACITORS OF DifFERENT GeOMETRIC SHAPE}

Capacitor heating occurs in all metallized film capacitors applications due to the passage of current. This heating is caused by the resistive and other types of losses taking place in the capacitor. Generally, this heating is undesirable and limits the life of the capacitor.

In view of the great difference between the dimensions of the material used in the MPP capacitor (a length of a few meters and a thickness of a few micrometers), it is difficult to determine the governing physics variables inside and around the element (magnetic and electric field, temperature, etc.).

Research work can be found in the literature concerning the homogeneity of the material forming the roll [7], [8]. Losses generated by current passage in the armatures and the dielectric losses cause the heating of the capacitor [2], [3]. The active

Paper IPCSD 01-079, presented at the 2000 Industry Applications Society Annual Meeting, Rome, Italy, October 8-12, and approved for publication in the IEEE TRANSACTIONS ON INDUSTRY APPLICATIONS by the Power Electronics Devices and Components Committee of the IEEE Industry Applications Society. Manuscript submitted for review October 15, 2000 and released for publication February 1, 2002.

M. H. El-Husseini, P. Venet, and G. Rojat are with CEGELY UMR 5005 CNRS, Université Claude Bernard de Lyon, 69622 Villeurbanne Cedex, France (e-mail: husseini@cegely.univ-lyon1.fr; venet@cegely.univ-lyon1.fr; rojat@cegely.univ-lyon1.fr).

C. Joubert is with the IUFM de Montpellier, 34092 Montpellier Cedex 5 , France (e-mail: joubert@univ-montp2.fr).

Publisher Item Identifier S 0093-9994(02)04506-1.

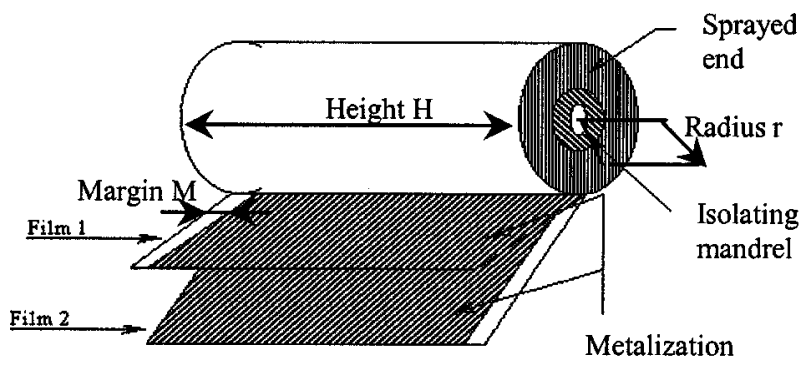

Fig. 1. General view of an MPP film capacitor.

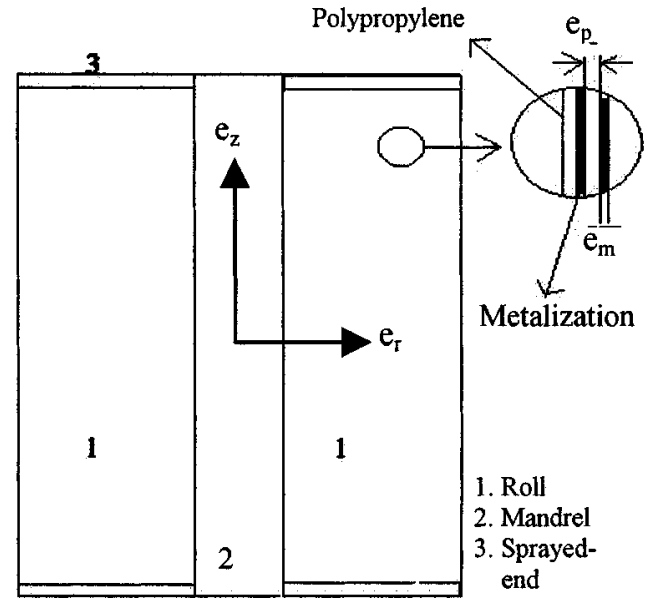

Fig. 2. Two-dimensional cross-sectional view of an MPP capacitor.

power consumed and the reactive power supplied in the volume $V$ of the roll can be obtained by [8]

$$
\begin{aligned}
& P=\iint_{V} \int P_{v}(r, z, \omega) d v \\
& \text { and } \\
& Q=\iint_{V} \int Q_{V}(r, z, \omega) d v
\end{aligned}
$$

where $P_{v}(r, z, \omega)$ and $Q_{v}(r, z, \omega)$ respectively represent the active and reactive volumetric power which depends on the radius " $r$ " of the roll, its height " $z$," and the electric frequency $\omega$ (Fig. 2). The active power consumed $D$ due to the dielectric is deduced from the reactive power

$$
D=Q \tan \delta
$$

where $\delta$ is the dielectric loss angle at the working frequency. Then, the total power dissipated is given by

$$
P_{\text {tot }}=P+Q \tan \delta \text {. }
$$


TABLE I

ChARACTERISTICS OF THE STUdied CAPACITORS

\begin{tabular}{c|c|c|c|c|c}
\hline & symbol & Group A & Group B & Group C & Group D \\
\hline Capacitance $(\mu \mathrm{F})$ & $\mathrm{C}$ & 10 & 10 & 10 & 10 \\
\hline Nominal Voltage $(\mathrm{V})$ & $\mathrm{U}_{\mathrm{n}}$ & 250 & 250 & 250 & 250 \\
\hline Margin $(\mathrm{mm})$ & $\mathrm{M}$ & 2.5 & 2.5 & 2.5 & 2.5 \\
\hline Film 1 thickness $(\mu \mathrm{m})$ & $\mathrm{e}_{\mathrm{p}}$ & 6 & 6 & 6 & 6 \\
\hline Metalization thickness $(\mathrm{nm})$ & $\mathrm{e}_{\mathrm{m}}$ & 15 & 15 & 15 & 15 \\
\hline Height $(\mathrm{mm})$ & $\mathrm{H}$ & 39.5 & 52 & 64 & 102 \\
\hline
\end{tabular}

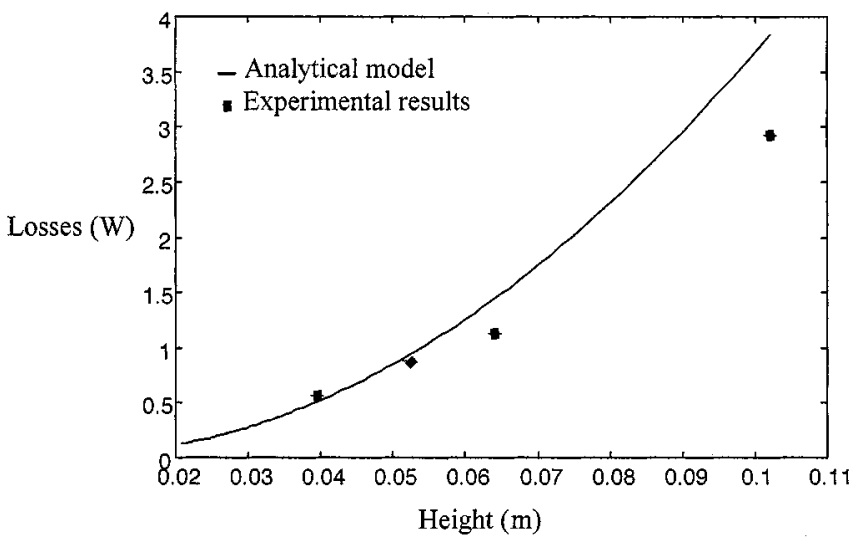

Fig. 3. Losses in an MPP capacitor versus the height $H$.

Analytical resolution of (1) and (2) uses the zeroth- and firstorder Bessel's functions and a numerical resolution with computer would need to be employed. This task has been accomplished earlier by one of the authors [8] and a software package has been developed for these computations.

Taking as a variable the total height of the capacitor $H$, Fig. 3 represents the total power dissipated $P_{\text {tot }}$ for a frequency of 40 $\mathrm{kHz}$ and a maximum current of $15 \mathrm{~A}$ calculated by the analytical model. At that frequency, the surface current distribution is practically independent of the distance " $r$ " from the axis of revolution of the capacitor. In order to validate the model and for four groups of capacitors having the same capacitance (10 $\mu \mathrm{F}$ ) but different height $H$ (the properties of which is given in Table I), the losses, shown in Fig. 3, are calculated by the equation

$$
P_{\mathrm{tot}}=\mathrm{ESR} \cdot I_{\mathrm{eff}}^{2}
$$

where ESR is the equivalent series resistance which represents the eddy and the dielectric losses and $I_{\text {eff }}$ the rms current value. The ESR value is measured by an impedance analyzer.

The model, as well as the experimental results, show that for the same current passing through the capacitor, the longer the capacitor, the greater is the power dissipated. This is due to the fact that, for a given frequency, the ESR of a short capacitor is smaller as compared to a long one having the same capacitance. This is illustrated in Fig. 4 which represent the ESR of the four groups of capacitors as a function of frequency (the value for each group is the average of five capacitors in that group).

As the ESR represents the eddy and dielectric losses, it is important to study its evolution since it determines the self-heating and, therefore, indirectly, the capacitor lifetime. Fig. 5 shows the

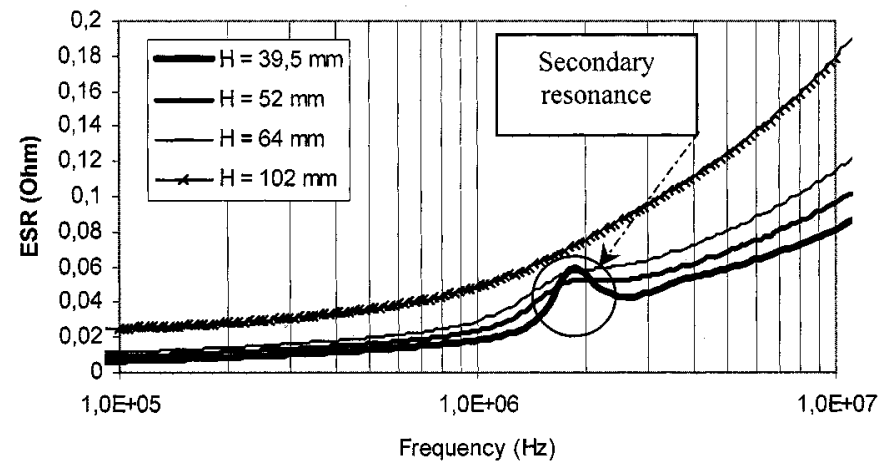

Fig. 4. ESR versus the frequency for capacitors of different height $H$.

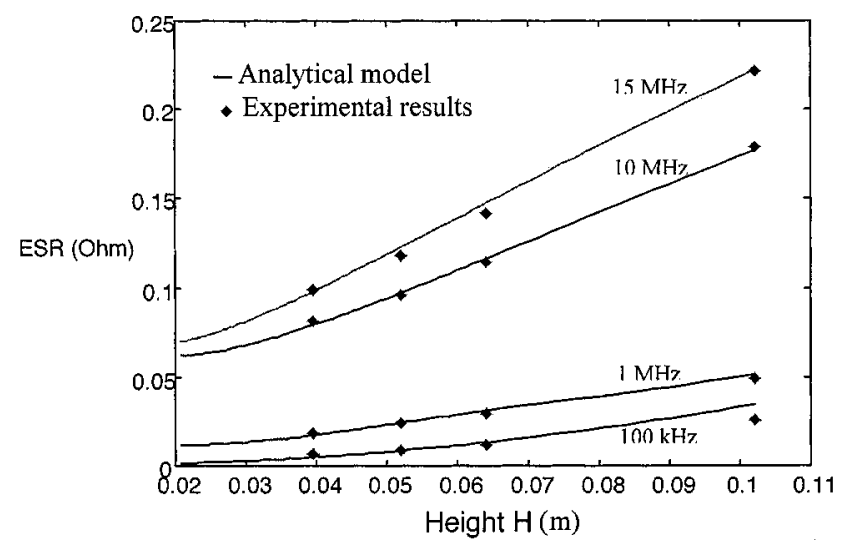

Fig. 5. ESR versus the height of the capacitor.

ESR value given by the model versus the capacitor height " $H$ " for different frequency values. In the same graph are shown the measured values of ESR for four groups of capacitors having the same capacitance $(10 \mu \mathrm{F})$ but different geometrical shape. There is a fairly good agreement between the model and the experimental results. As mentioned above, it is observed that a long capacitor (having a large $H$ dimension) has an ESR value higher than the ESR value for a shorter capacitor having the same capacitance.

Given that the ESR indicates self-heating, it seems logical to expect that compared to a short capacitor, subject to the same electric stresses, the long capacitor will undergo more heating.

We can note that the MPP capacitors exhibit secondary resonance (see Fig. 4) at frequency beyond the self-resonant frequency (of the order of $250 \mathrm{kHz}$ ). For the long capacitors of relatively higher ESR the secondary resonance has not been observed. 


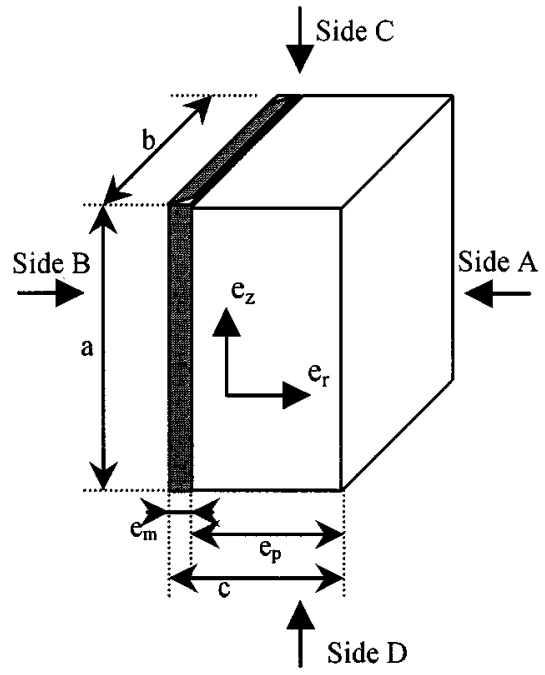

Fig. 6. A small element of the metallized film used to calculate the thermal conductivity of anisotropic nature.

\section{RESUlts OF THE THERMAl Simulation FOR FouR CAPACITORS OF DIFFERENT GEOMETRY}

In the following is presented the results of steady-state thermal simulations of the two-dimensional heat equations by finite-element analysis (using code Flux2d). Our objective is to find the temperature distribution inside the roll which would help us to better understand the relationship between the geometry of the capacitor and its heating. The sinusoidal current $I$ passing through the capacitor has a maximum value of $15 \mathrm{~A}$ at the frequency of $40 \mathrm{kHz}$ and dissipates power $P_{\text {tot }}$. The heat dissipated will be conducted to the outside of the roll where it must then be eliminated by natural or forced convection as well as by radiation.

This heat transfer depends upon the macroscopic thermal conductivity of the polypropylene layers and the metallization as well as the geometry of the roll [7], [8].

\section{A. Conduction Heat Transfer}

In order to calculate the macroscopic thermal conductivity coefficient of the roll we will take into account the fact that a heat flux parallel to the revolution axis of the roll ( $e_{z}$ axis) will be transferred easily through the metallization layers, which have a large thermal conductivity, from one sprayed end to the other. A radial heat transfer (according to the $e_{r}$ axis) will be more difficult because of the significant thermal resistance of the polymer layers.

Fig. 6 represents a small element of the roll. Letting $\lambda_{p}$ represent the thermal conductivity of the polypropylene and $\lambda_{m}$ that of the metal (zinc or aluminum), $e_{p}$ the thickness of the polypropylene, and $e_{m}$ that of the metal, then the thermal resistance of the element between $A$ and $B$ sides is [8]

$$
R_{A B}=\frac{1}{\lambda_{p}} \frac{e_{p}}{a b}+\frac{1}{\lambda_{m}} \frac{e_{m}}{a b} .
$$

The thermal conductivity $\lambda_{r}$ about the axis $e_{r}$ is given by

$$
\lambda_{r}=\frac{1}{R_{A B}} \frac{c}{a \cdot b}=\frac{c}{\frac{e_{p}}{\lambda_{p}}+\frac{e_{m}}{\lambda_{m}}}=\frac{e_{p}+e_{m}}{\frac{e_{p}}{\lambda_{p}}+\frac{e_{m}}{\lambda_{m}}} .
$$

If it is assumed that $e_{m} \ll e_{p}$ and $\lambda_{m} \gg \lambda_{p}$ we can say that

$$
\lambda_{r} \approx \lambda_{p}
$$

Then, the radial thermal conductivity of the roll is approximately the same as that of the polymer. The thermal resistance of the same element taken between the $C$ and $D$ sides is

$$
R_{C D}=\left[\lambda_{p} \frac{e_{p} b}{a}+\lambda_{m} \frac{e_{m} b}{a}\right]^{-1} .
$$

From (9), it follows that the thermal conductivity of the roll about the axis $e_{z}$ is given by

$$
\lambda_{z}=\frac{1}{R_{C D}} \frac{a}{b c}=\frac{e_{p} \lambda_{p}+e_{m} \lambda_{m}}{e_{m}+e_{p}} \approx \lambda_{p}+\frac{e_{m}}{e_{p}} \lambda_{m} .
$$

For a capacitor made of a film of $6-\mu \mathrm{m}$ thickness and metallized with a 15-nm-thick zinc layer, the axial conductivity is approximately two times larger than the radial conductivity. It follows that, although the metallization layer is thin, it modifies strongly the thermal behavior of the capacitor.

Starting from the anisotropic thermal conductivity of the material, it is possible calculate out the temperature distribution in the roll for a given value of the volumetric power density produced by eddy and dielectric losses. The general conduction heat equation is [10]

$$
\nabla^{2} T+\frac{\chi}{\lambda}=\frac{\delta C_{p}}{\lambda} \frac{\partial T}{\partial t}
$$

where $\nabla^{2}$ is the Laplacian operator, $T$ is the spatial temperature distribution, $\delta$ is the material density, $\lambda$ is the material thermal conductivity, $\chi$ is the local volumetric power density, $C_{p}$ is the specific heat, and $t$ is time. When the steady-state solution is sought, the transient term on the right-hand side of (11) is zero. In cylindrical coordinates, for the steady-state solution, we multiply by $\lambda$ to obtain

$$
\frac{\lambda}{r} \frac{\partial}{\partial r}\left[r \frac{\partial T}{\partial r}\right]+\lambda \frac{\partial^{2} T}{\partial z^{2}}+\chi=0 .
$$

Since we are considering an anisotropic medium, we should use axial and radial conductivities separately. Fortunately, (12) is in a separable form with respect to the space variables and this is straightforward. Equation (12) can be written as

$$
\frac{\lambda_{r}}{r} \frac{\partial}{\partial r}\left[r \frac{\partial T}{\partial r}\right]+\lambda_{z} \frac{\partial^{2} T}{\partial z^{2}}+\chi=0 .
$$

Unfortunately, (13) is impossible to solve in closed form for most interesting cases. If we assume $\chi=0$ (no internal power generation) and provide surfaces with simple boundry conditions, the temperature can be written as

$$
\begin{aligned}
T(r, z)=\sum_{i}^{\infty} \sum_{j}^{\infty} & \left\{\left[a_{i} J_{0}\left(\frac{k_{r}}{\sqrt{\lambda_{r}}}\right)+b_{i} Y_{0}\left(\frac{k_{r}}{\sqrt{\lambda_{r}}}\right)\right]\right. \\
\bullet & {\left.\left[c_{j} J_{0}\left(\frac{k_{z}}{\sqrt{\lambda_{z}}}\right)+d_{j} Y_{0}\left(\frac{k_{z}}{\sqrt{\lambda_{z}}}\right)\right]\right\} }
\end{aligned}
$$

where $J_{0}$ and $Y_{0}$ are the zeroth-order Bessel and Weber functions, respectively. $a, b, c, d$, and $k$ are constants that depend on the initial conditions. It was, therefore, concluded fairly early in 
our thermal modeling that computer solutions would need to be employed.

\section{B. Convection Heat Transfer}

The mode of heat transfer from the capacitor to the ambient environment may include conduction, convection, and radiation. Conduction is a volumetric parameter and includes path length as well as cross-sectional area effects, as has already been discussed. Externally, conduction is a significant mode only when the capacitor is attached to a heat sink. Convection, on the other hand, is generally modeled as a surface effect, although the localized film thickness and velocity (hydrodynamic) and temperature (thermodynamic) distributions extend beyond the surface. The parameter that describes the degree of thermal heat transfer coupling from a surface of area $A$ to the ambient fluid is known as the convection or film coefficient $h_{c}$, which is a function of the fluid velocity and mass transfer properties, such as density and viscosity. If the surface is at a higher temperature than the environment by an amount $\Delta T$, the power $P_{\mathrm{CONV}}$ dissipated through convection is given by

$$
P_{\mathrm{CONV}}=h_{c} A \Delta T
$$

Although (15) holds for virtually any fluid, this paper deals only with air at standard atmospheric pressure and at ambient temperature.

To simulate the phenomenon of convection, one needs to calculate the convection heat transfer coefficient of each side of the roll to be used in a finite-element analysis software package. For that purpose, let us denote the dimensionless average Nusselt and Grashof numbers as $N u$ and $G r$, respectively. A subscript of $D$ or $L$ is generally used along with the numbers to indicate application to a cylinder or plate, respectively. In addition, there is a dimensionless number $P r$, the Prandtl number, which describes the medium and has a negligible temperature variation in our case. The convection coefficient is then given by [9]

$$
h_{c}=\frac{\lambda N u}{D}
$$

where $\lambda$ is the thermal conductivity of the air. An experimental Nusselt number expression is given by

$$
N_{u}=B G_{r}^{n} P_{r}^{p}
$$

where $n, p$, and $B$ are corrective coefficients chosen in such a manner as to represent, as correctly as possible, the experimental results. In the case of a laminar natural convection regime, it is experimentally proven that $n$ and $p$ are practically the same for all systems and that $B$ depends only on the shape of the exposed sides. Knowing that the Grashof number is given by

$$
G r=\frac{g \beta D^{3} \Delta T}{\nu^{2}}
$$

where $g$ is the gravitational acceleration, $\beta$ dilatation coefficient of the air at constant pressure, $\nu$ the kinematic viscosity of the air, and $\Delta T$ is the temperature difference between the surface
TABLE II

CORRECTIVE NumBers FOR HEAT TRANSFER CONVECTION

\begin{tabular}{l|c|c|c}
\hline \multirow{2}{*}{} & \multirow{2}{*}{ Vertical plane surface } & \multicolumn{2}{|c}{ Horizontal plane surface } \\
\cline { 3 - 4 } & & Top surface & Bottom surface \\
\hline $\mathrm{n}$ & 0.25 & 0.25 & 0.25 \\
\hline $\mathrm{p}$ & 0.25 & 0.25 & 0.25 \\
\hline $\mathrm{B}$ & 0.59 & 0.54 & 0.27 \\
\hline $\mathrm{Pr}$ & 0.72 & 0.72 & 0.72 \\
\hline
\end{tabular}

TABLE III

PHYSICS PROPERTIES OF THE AIR

\begin{tabular}{c|c|c|c}
\hline$\delta$ & density & 1.177 & $\mathrm{Kg} / \mathrm{m}^{3}$ \\
\hline$\mu$ & Dynamic viscosity & $1.85 \mathrm{E}-5$ & $\mathrm{Kg} / \mathrm{m} . \mathrm{s}$ \\
\hline$\nu$ & Kinematical viscosity & $1.57 \mathrm{E}-5$ & $\mathrm{~m}^{2} / \mathrm{s}$ \\
\hline $\mathrm{Cp}$ & Specific heat & $1.006 \mathrm{E}+3$ & $\mathrm{~J} / \mathrm{kg} . \mathrm{K}$ \\
\hline$\lambda$ & Thermal conductivity & $2.62 \mathrm{E}-5$ & $\mathrm{~W} / \mathrm{m} . \mathrm{K}$ \\
\hline
\end{tabular}

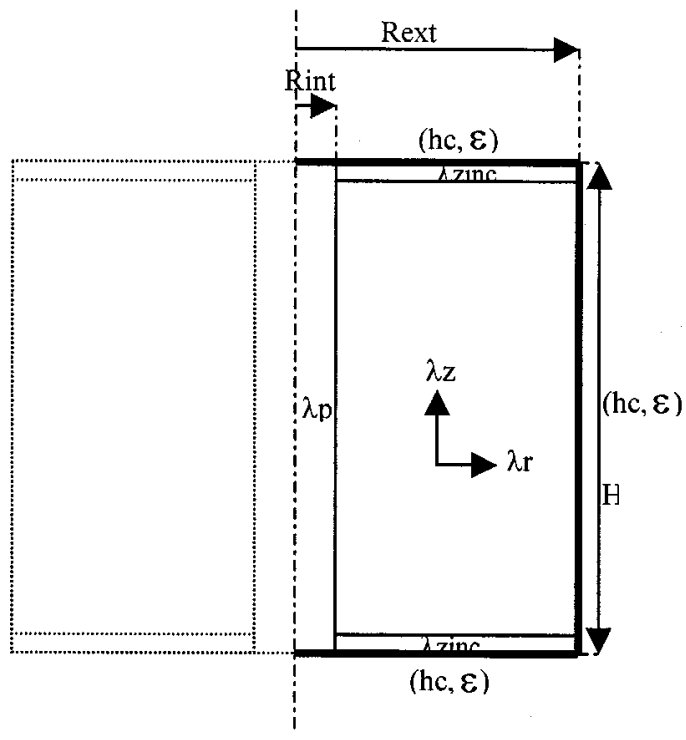

Fig. 7. Element used for simulation.

and the ambient air temperature, the convection coefficient becomes

$$
h_{c}=\frac{\lambda}{D} B \frac{g^{n} \beta^{n} \Delta T^{n} D^{3 n}}{\nu^{2 n}} \operatorname{Pr} p
$$

Table II represents accepted approximate values of $n, p, B$, and $P r$ in the case of a laminar natural convection mode for different geometrical arrangements at normal atmospheric pressure and ambient temperature $\left(27^{\circ} \mathrm{C}\right)$. We note that for a horizontal plane surface the number $B$ is not the same for the top and the bottom surface. It is worthy to note that those values are given for a surface whose temperature is greater than the ambient surrounding fluid's temperature. Table III gives useful physical constants of air at $300 \mathrm{~K}$ and normal atmospheric pressure.

\section{Radiation Heat Transfer}

Radiation, like convection, is also a surface-to-environment effect. The radiation heat transfer is dependent not only on the temperature difference between a surface and its environment, 


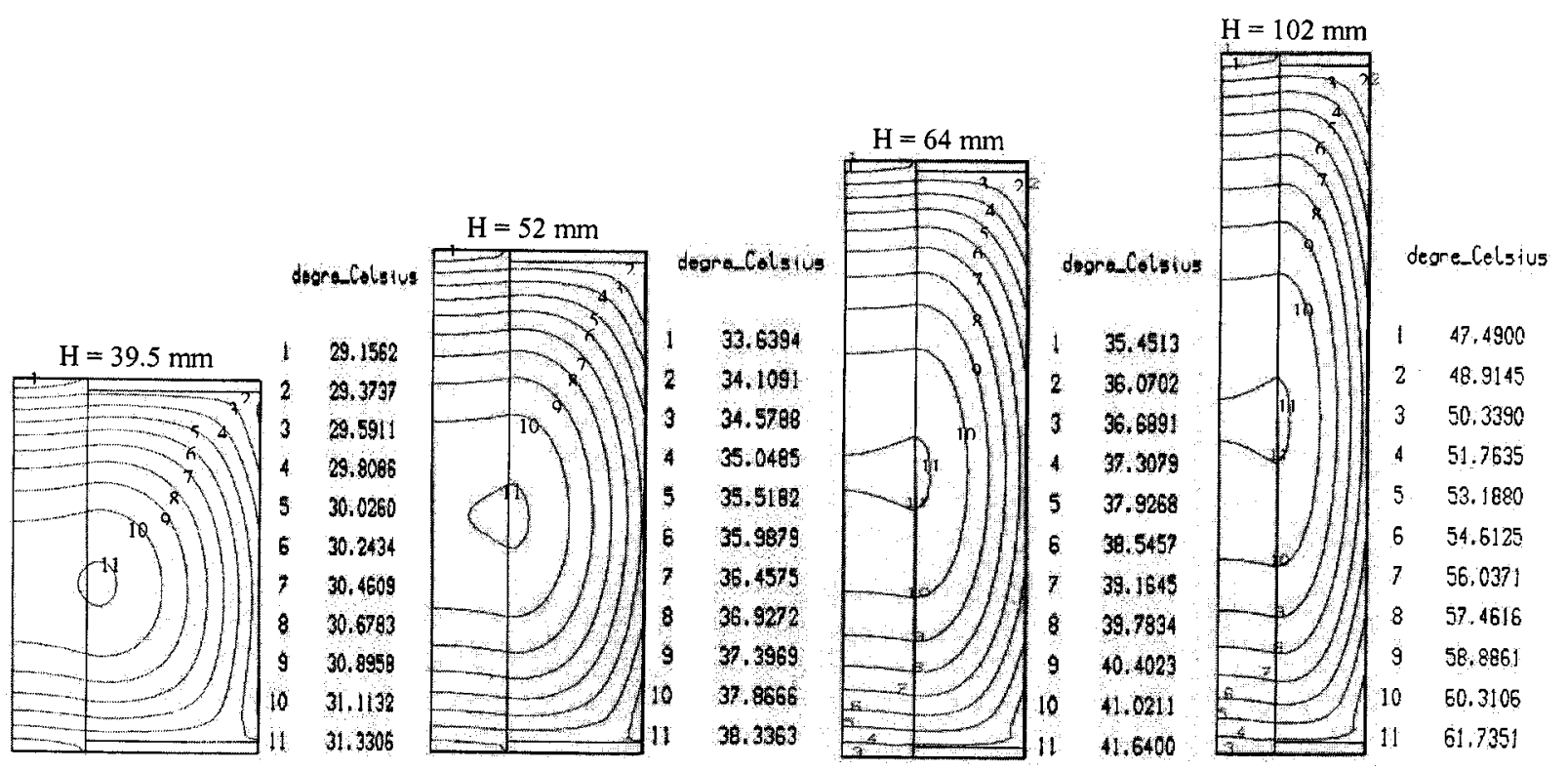

Fig. 8. Temperature distribution for four capacitors of different height $H$.

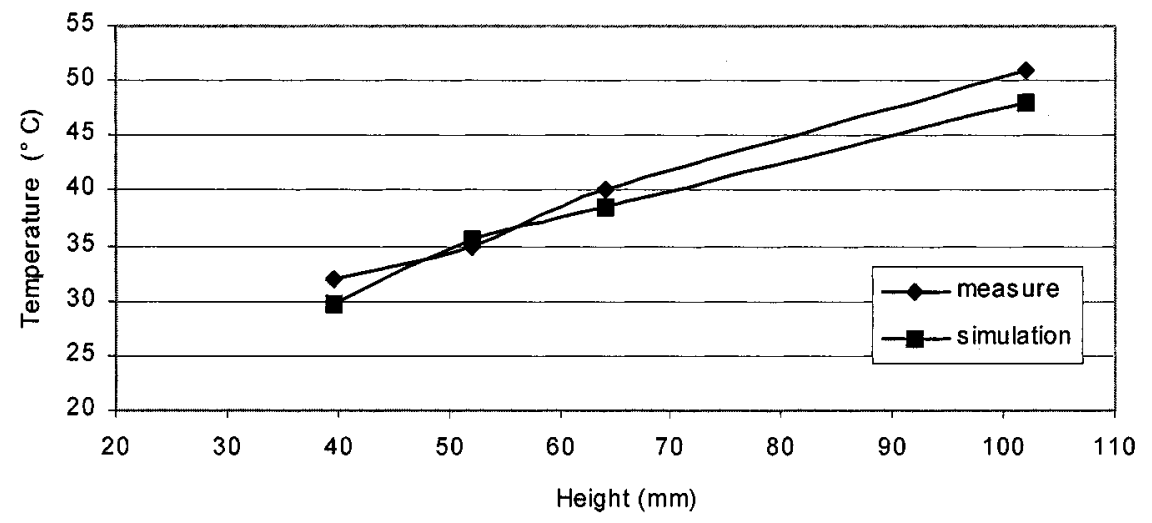

Fig. 9. Surface temperature of four capacitors (simulated and measured).

but also on the absolute temperatures involved. The surface emissivity $\varepsilon$ is also important in radiation heat transfer. The power $P_{\mathrm{RAD}}$ transferred from a surface area $A$ at temperature $T_{s}$ to an environment at temperature $T_{\infty}$ due to radiation is [10]

$$
P_{\mathrm{RAD}}=\varepsilon \sigma A\left(T_{s}^{4}-T_{\infty}^{4}\right)
$$

where $\varepsilon$ is the surface emissivity (value between zero to one) in the infrared region of the electromagnetic spectrum and $\sigma=$ $5.67 \times 10^{-8} \mathrm{~W} / \mathrm{m}^{2} \mathrm{~K}^{4}$ is the Stefan-Boltzmann constant. Simulations are made assuming that $\varepsilon=0.8$. Equation (20) may be put into a form equivalent to (15) by factoring out $\Delta T=$ $\left(T_{s}-T_{\infty}\right)$, yielding

$$
P_{\mathrm{RAD}}=h_{\mathrm{RAD}} A \Delta T
$$

where

$$
h_{\mathrm{RAD}}=\varepsilon \sigma\left(T_{s}+T_{\infty}\right)\left(T_{s}^{2}+T_{\infty}^{2}\right) .
$$

It can be seen from (22) that the radiation coefficient $h_{\mathrm{RAD}}$ increases with both increasing the surface and environment temperatures. Radiation heat transfer can be significant compared to natural convection alone. Generally, the convection coefficient $h_{c}$ for natural convection, like the radiation coefficient $h_{\mathrm{RAD}}$, varies from about 2 to about $4 \mathrm{~W} / \mathrm{m}^{2} \mathrm{~K}$, for capacitors of this size and temperature range.

The simulation is performed for one-half of a two-dimensional section of the capacitor. The input parameters for the model are the radial and the axial conduction heat transfer coefficients $\lambda_{r}$ and $\lambda_{z}$, respectively, and the convection heat transfer coefficient and radiation emissivity $h_{c}$ and $\varepsilon$, respectively, as shown in Fig. 7.

The results of simulation are shown in Fig. 8. The power dissipated is supposed to be uniformly distributed in the roll. It is observed that the short capacitor heats up less compared to the long capacitor when both are subjected to the same electric stresses. This is due to the fact that long capacitors have a higher ESR value as discussed earlier in this paper. It appears that a simple physical explanation is possible: the current must travel a longer distance, through the very thin metal films, in the long capacitors, thus, the total $I^{2} R$ (which is proportional to ESR) is higher compared to a short capacitor.

In order to validate the simulation, electric stresses were applied for the four groups of capacitors with an identical mechanism of heat evacuation (vertical position at the surrounding 
temperature of $24{ }^{\circ} \mathrm{C}$ ). The surface temperature measurement is done with the help of a thermocouple. Fig. 9 represents the experiment and simulation results.

\section{CONCLUSION}

There is a good agreement between the simulation and the experimental results. A more accurate study of the temperature distribution in the rolled MPP capacitors would employ a nonuniform loss distribution.

However, the results obtained at the frequency of $40 \mathrm{kHz}$ are quite satisfactory and give a good idea of the thermal behavior of the MPP film capacitors.

\section{ACKNOWLEDGMENT}

The authors would like to express their thanks to "Le condensateur PRELYO" company for supplying the metallized polypropylene film capacitors and for their technical support.

\section{REFERENCES}

[1] W. J. Sarjeant, "Capacitors," IEEE Trans. Elect. Insulation, vol. 25, pp. 861-894, Oct. 1990.

[2] C. Bateman, "Power dissipation in capacitors," Electron. Wirel. World, vol. 101 , no. 1709 , pp. 287-290, 1995 .

[3] B. Seguin, J. P. Gosse, A. Sylvestre, P. Fouassier, and J. P. Ferrieux, "Calorimetric apparatus for measurement of power losses in capacitors," in Proc. IEEE IMTC'98, vol. 1, May 1998, pp. 602-607.

[4] Condensateurs utilisés en Électronique de puissance, Technique de l'ingénieur, D4 II D644, 1995.

[5] "Recommandations pour l'utilization du film de polypropylène métallisé en condensateur," Bolloré Technologie Industrie, France, Notice Tech., May 1989.

[6] R. Besson, Technologie des Composant Électronique, 6th ed. Paris, France: SECF Editions Radio, 1990, vol. I.

[7] E. Matagne, "Contribution à la modélization de dispositifs Électromagnétiques en vue de leur optimization," Ph.D. dissertation, Univ. Catholique Louvain, Louvain, Belgium, 1991.

[8] C. Joubert, "Etude des phénomènes Électromagnétiques dans les condensateurs à films métallisés-Nouvelle génération des condensateurs," Ph.D. dissertation, École Centrale Lyon, Lyon, France, 1996.

[9] Ch. Bory, Les Échanges de Chaleur par Convection. Paris, France: Energétiques BORDA/MOUTON, 1968, vol. I.

[10] A. B. De Vriendt, La Transmission de la Chaleur, 3rd ed, G. Morin, Ed. Quebec, QC, Canada: Gaëten morin, 1990, vol. I and II.

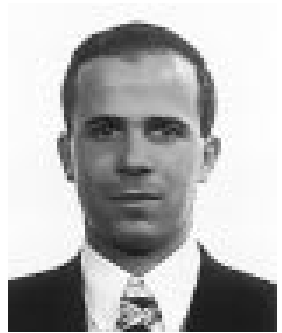

M. H. El-Husseini was born in Baalbeck, Lebanon, in 1974. He received the M.Sc. degree in electronics from the Lebanese University, Beirut, Lebanon, in 1996 and the Post-Graduate and Ph.D. degrees in electrical engineering from the École Centrale de Lyon and the Université Claude Bernard de Lyon, Lyon, France, in 1997 and 2001, respectively.

His major area of interest concerns the study of MPPF capacitors as related to their thermal optimization and aging processes.

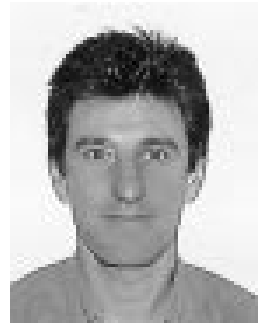

film capacitors.

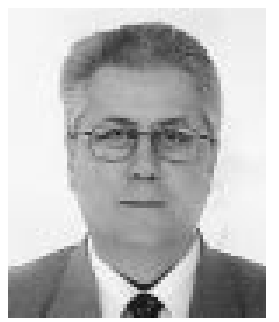

Gérard Rojat was born in Caraman, France, in 1946. He received the Master's and Doctor's degrees from the Université Paul Sabatier, Toulouse, France, in 1971 and 1974, respectively, and the Ph.D. degree in electrical engineering from the Université Claude Bernard de Lyon, Lyon, France.

He was an Assistant Professor at the École Centrale de Lyon for 23 years. He is currently a Senior Professor at the Université Claude Bernard de Lyon. $\mathrm{He}$ is the author or coauthor of more than 80 scientific papers.

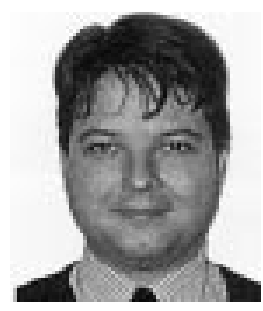

Charles Joubert was born in Avignon, France, in 1970. He received the M.S. degree from the University of Paris XI, Orsay, France, and the Ph.D. degree from the École Centrale de Lyon, Écully, France, in 1991 and 1996, respectively.

Since 1997, he has been an Associate Professor at the IUFM de Montpellier, Montpellier, France, and is currently with the Laboratoire d'Electrotechnique de Montpellier (LEM). His major field of interest is the understanding of electromagnetic phenomena taking 